\title{
Chegamos! Então sigamos ...
}

\author{
We have got there! Now, we should move on.
}

\author{
Harley E. A. Bicas, Wallace Chamon
}

\section{Chegamos!}

Por tudo o que significa em termos de qualificação e reconhecimento de valores, pela rigorosa seletividade dos julgamentos que levam a esse resultado, o acolhimento de uma revista científica pelo ISI (Institute for Scientific Information) Web of Knowledge, representa-lhe o mais cobiçado objetivo a ser alcançado, a indexação definitiva. De fato, essa agência de catalogação da produção científica mundial, tradicional e historicamente respeitada, a mais antiga, independente e criteriosa, incorporou a essa análise métodos e indicadores (dos quais, provavelmente, o mais famoso é o do fator de impacto), que passaram a referenciais de diferenciação entre as mais diversas publicações. Um guia, "o" guia de apreciação de seus atributos.

No Brasil, principalmente, as agências de fomento à pesquisa acadêmica e as Universidades, suas produtoras, assumiram tais critérios com tal entusiasmo a ponto de, praticamente, lhes deixar subordinados os vários apoios financeiros e influenciar docentes universitários sobre o direcionamento de seus desempenhos profissionais. Mas reações a essa indução tornaram-na objeto de polêmica. Recentemente, aliás, voltamos ao assunto em novo editorial, para antagonizar o recrudescimento dessa postura pela CAPES, com reflexos diretos sobre as revistas científicas brasileiras. Em seguida, a Associação Médica Brasileira e a Academia Brasileira de Editores Científicos promoveram reuniões de editores científicos sobre tal assunto de inequívoca relevância.

Assim, chegar ao ISI, havendo já conquistado os reconhecimentos da SciELO, da MEDLINE (PubMed), da EMBASE, do Scopus, entre outros indexadores, deve ser motivo de júbilo e de comemorações. Representa a coroação da Oftalmologia brasileira pelo que tem sido considerado o fator mais importante de valoração das publicações científicas. Artigos brasileiros chegam a uma quantidade muito maior de leitores e as medidas dos artigos publicados nos Arquivos Brasileiros de Oftalmologia chegam a um novo patamar de reconhecimento por nossas agências de fomento e Universidades.

Enfim, alcançamos. E desde 2008 (os 156 artigos publicados por nossa revista nesse ano já estão sendo avaliados pelo ISI e, em seguida, os de 2009 e futuros). Essa honra, a de única revista de Oftalmologia da América Latina a usufruir do privilégio de estar indexada nas duas maiores entidades da literatura científica mundial (ISI e PubMed), além da maior entidade latino-americana (SciELO) deve fartar de orgulho a todos os brasileiros, principalmente nós, seus oftalmologistas. Um atestado do alto nível de nossos conhecimentos e procedimentos da especialidade, refletidos nas publicações veiculadas pelos A.B.O.

A indexação coloca novos observadores sobre tudo o que é escrito na literatura oftalmológica brasileira. Agora passamos a ser avaliados sistematicamente, principalmente em relação à importância das nossas publicações para os outros autores, nacionais e internacionais. A partir de 2011, será medida a quantidade de vezes que cada artigo escrito nos A.B.O. surgir referido pela literatura mundial (e também brasileira) em uma base de dados que inclui 45 revistas relacionadas à oftalmologia. O próximo passo são as metas! Essas só serão atingidas com esse trabalho árduo da comunidade científica brasileira em publicar, cada vez mais, artigos de alta qualidade e relevância nos A.B.O.

Certamente, a conquista é, sim, da Oftalmologia brasileira. Foi por sua excelência que chegamos a mais essa vitória. Autores e analistas das respectivas matérias da revista fizeram um belo trabalho. A equipe editorial, toda, articulando-os e supervisionando-os, garantiram a qualidade do que veio à luz, complementada pela indispensável normatização, pela cuidadosa revisão gráfica final, pelo diuturno trabalho da secretaria. Uma fortíssima equipe, essa, a que merece cumprimentos e celebrações. Finalmente, na tarefa de postulação desse reconhecimento e de acompanhamento de seus resultados, um especial destaque deve ser dado ao comprometimento de Paulo Elias Correa Dantas e Edna Terezinha Rother.

Sabemos que ainda temos que melhorar muito, principalmente no que se refere aos indicadores de eficiência da nossa revista, como o tempo necessário para a publicação dos manuscritos enviados. Para isso contamos com um dos trabalhos menos valorizados e reconhecidos mundialmente: a editoração científica realizada pelos nossos pares. Esses, muitas vezes anônimos, co-editores, editores associados, membros do conselho editorial e revisores "ad hoc" dos A.B.O., que dispensam horas do seu trabalho na avaliação e melhora dos artigos enviados para a publicação.

A história não acaba. É como, a um clube, chegar à divisão de elite, a um pequeno e seletíssimo grupo. Os holofotes, agora, serão mais intensos sobre os A.B.O. e o objetivo, agora, é o de distinguir-se nessa categoria, disputando o campeonato dos indicadores. E o que precisamos, para isso? Não muito mais! 
Apenas, que nos conscientizemos de que boa parte de nossa melhor produção seja agora direcionada aos A.B.O. (não há mais razões para evitar esse encaminhamento), sem deixá-la que se escoe a revistas estrangeiras, fortalecendo-as ainda mais. Isto é, que marquemos para nosso time, não que façamos gol contra... Apenas, que autores brasileiros não se pejem de citar nossos artigos, nem se enciúmem de que eles sejam assinados por patrícios. Apenas, enfim, que acreditemos que podemos.

\section{Então, sigamos!}

